\title{
The Oxford High Density Tunnel (HDT)
}

\author{
M. McGilvray ${ }^{1}$, L. J. Doherty ${ }^{1}$, A. J. Neely², P. T. Ireland ${ }^{1}$ and R. Pearce ${ }^{1}$ \\ ${ }^{1}$ Osney Thermofluids Laboratory, The University of Oxford, United Kingdom \\ ${ }^{2}$ School of Engineering \& Information Technology, UNSW, Australia
}




\section{NWTF Program Overview}

- One of three high speed tunnels being installed and commissioned at the Osney Thermofluids Laboratory:

- T6 Stalker Tunnel - High total enthalpy tunnel

- High Density Tunnel - High Reynolds number

- Low Density Tunnel - Rarefied tunnel
- Funded through National Wind Tunnel Facility (NWFT) scheme

- Partnership between 7 universities and EPSRC/ATI

- Allow for min. 25\% access to outside bodies (academic or commercial) use of facilities and instrumentation.

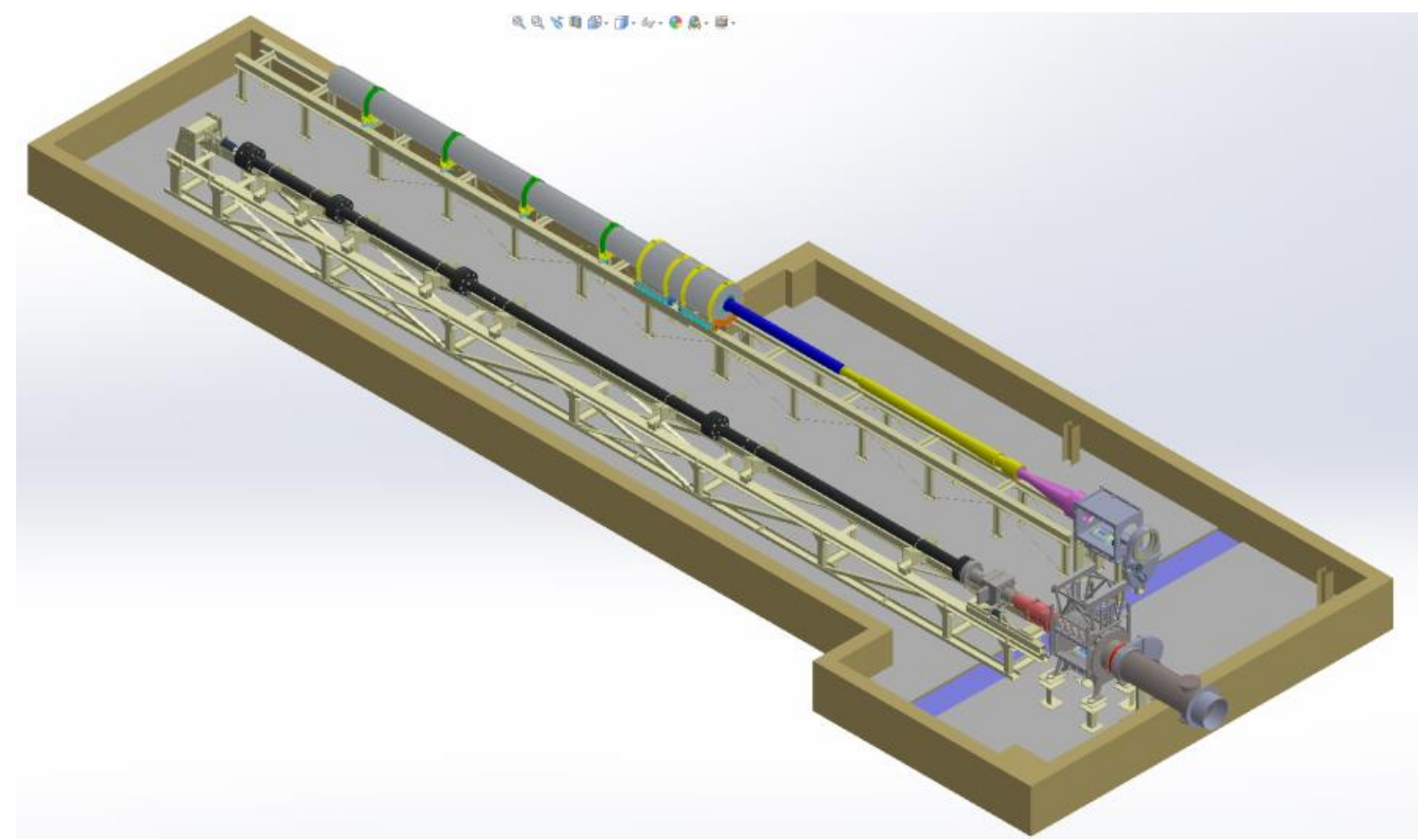




\section{History}

- Originally developed at the RAE in United Kingdom in the 1960s

- Initially operated as a cold hydrogen driven shock tube

- Extended to included reflected shock tunnel mode. Operated in this mode until mid-1980s.

- Converted to a Ludwieg tube with the capability of using Light Piston Compression Heating ( $\mathrm{LICH}$, [1]).

- External heating and a fast acting valve added in the early 1990s.

- Used by Qinetiq to support the HyShot [2] and SHyFE [2] flight experiments.

- Acquired from Qinetiq in 2012 by The University of Oxford

- Currently undergoing installation with initial operation and commissioning expected in the second half of 2015

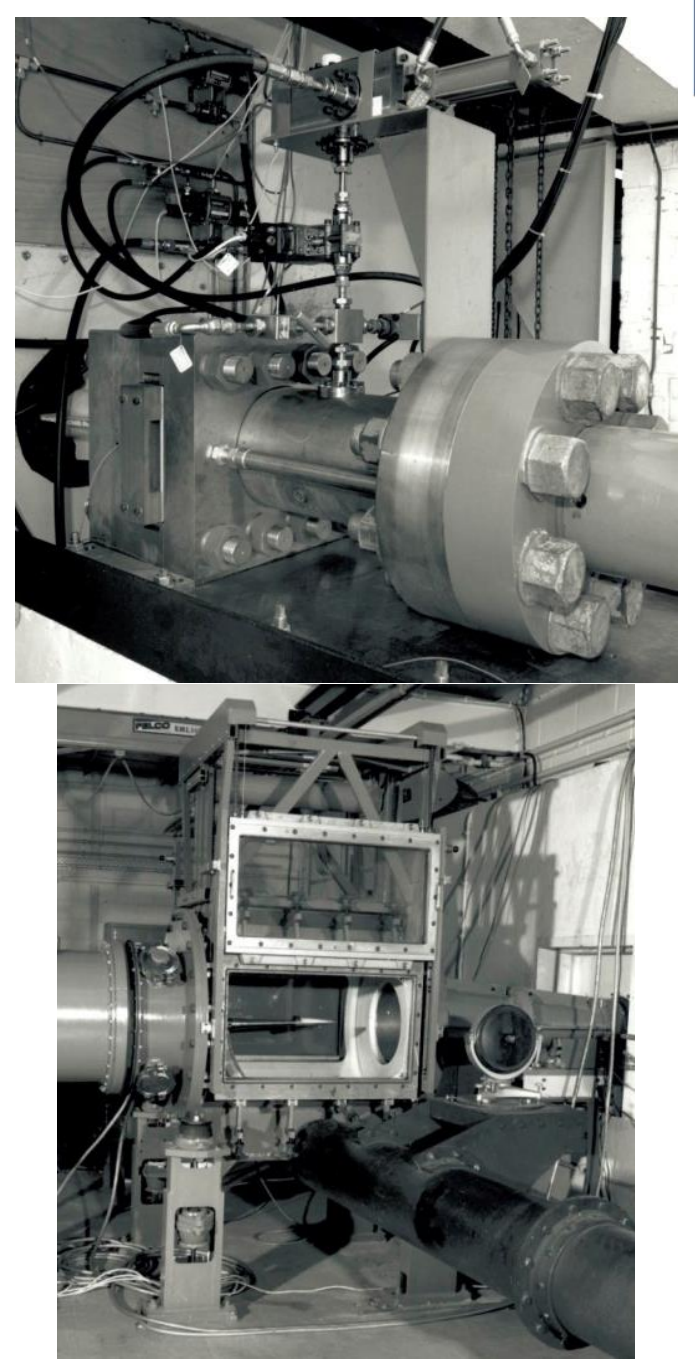




\section{NWTF Facility Description}

- Cold hypersonic flow facility for steady and unsteady aerothermodynamic testing

- Test durations up to $70 \mathrm{~ms}$

- $6.5 \mathrm{~m}$ long, $152 \mathrm{~mm}$ diameter driver

- $\quad 17.4 \mathrm{~m}$ long, $152 \mathrm{~mm}$ diameter barrel

- Mach 3, 4, 5, 6, and 7 contoured nozzles

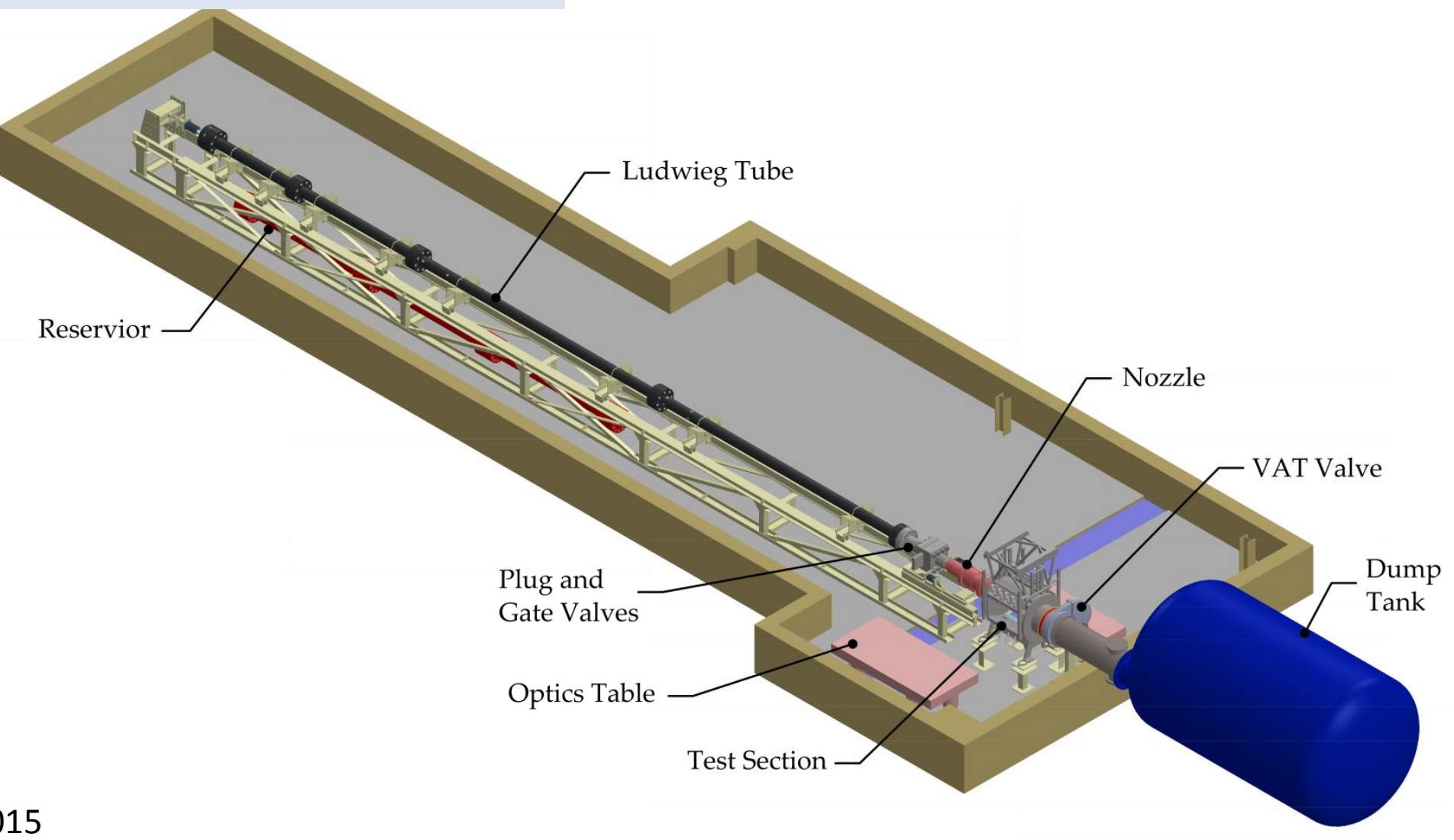




\section{NWTF Facility Description}

- Cold hypersonic flow facility for steady and unsteady aerothermodynamic testing

- Test durations up to $70 \mathrm{~ms}$

- $6.5 \mathrm{~m}$ long, $152 \mathrm{~mm}$ diameter driver

- $\quad 17.4 \mathrm{~m}$ long, $152 \mathrm{~mm}$ diameter barrel

- Mach 3, 4, 5, 6, and 7 contoured nozzles
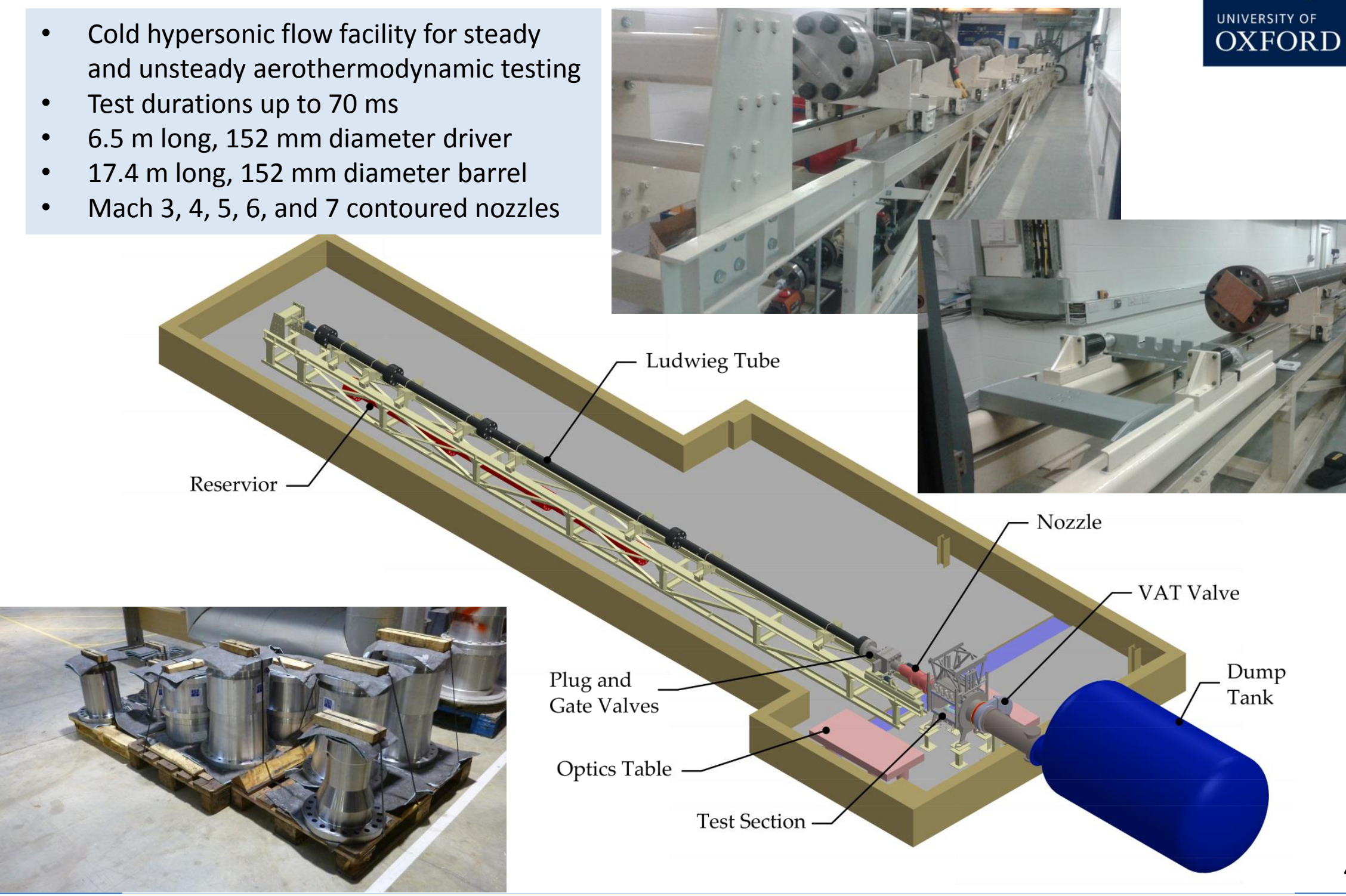


\section{Operational Envelope}

- Three operating modes:

1. Ludwieg tube mode

2. LICH mode un-heated

3. $\mathrm{LICH}$ mode heated
- Keep test gas above liquefaction at nozzle exit

- Ensure that the test section remains subatmospheric

\section{$T_{\text {wall }} T_{0}$}

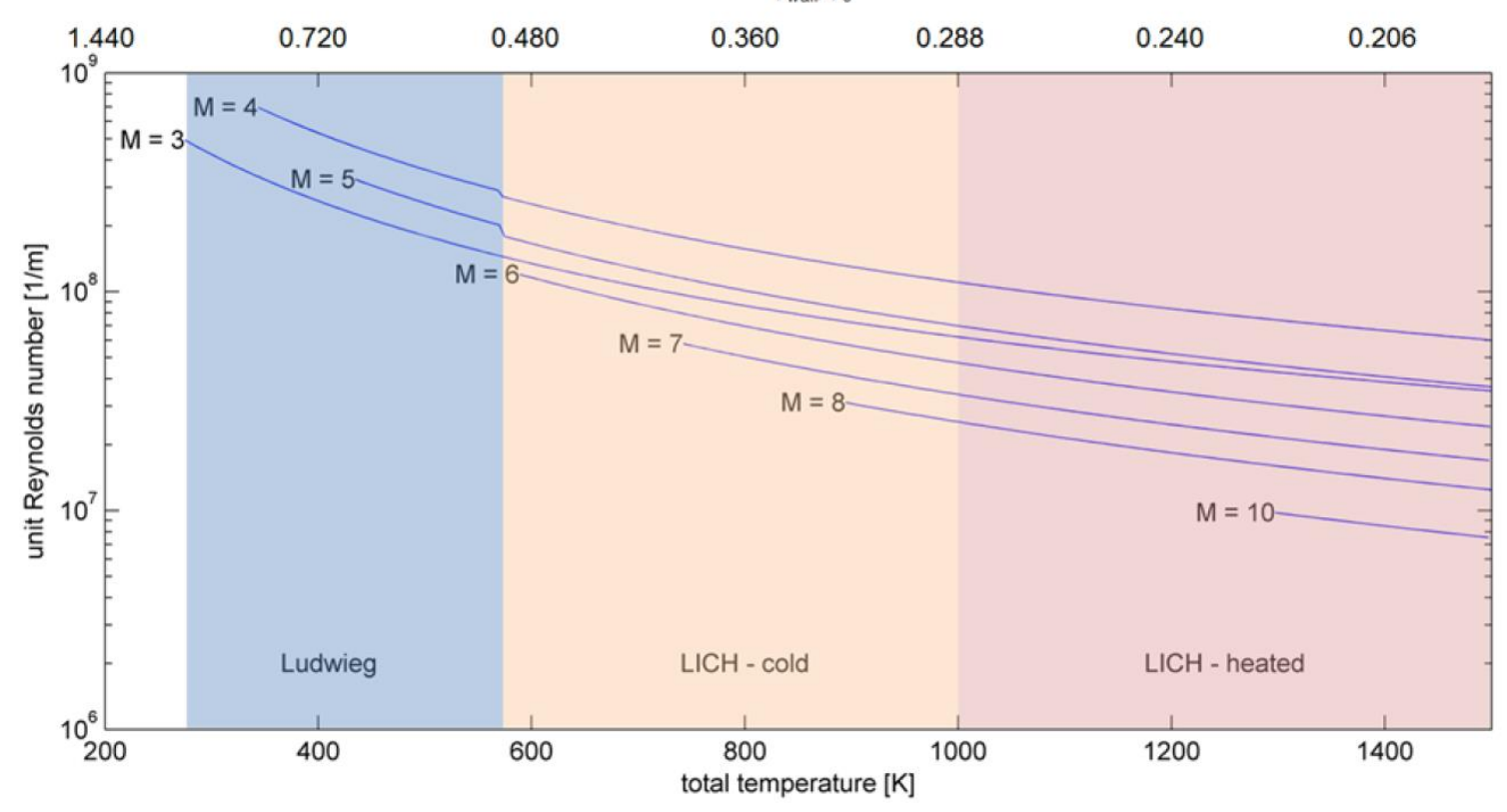

\begin{tabular}{lccccc}
\hline Property & Mach 3 & Mach 4 & Mach 5 & Mach 6 & Mach 7 \\
\hline Operation Mode & \multicolumn{2}{c}{ Ludwieg } & Ludwieg/LICH & LICH \\
Max. Total Pressure $($ bar $)$ & 30 & 95 & 100 & 90 & 90 \\
Min. Total Temperature $(\mathrm{K})$ & 288 & 360 & 454 & 580 & 750 \\
Max. unit Reynolds number $\left(10^{6} / \mathrm{m}\right)$ & 493 & 694 & 326 & 120 & 58 \\
\hline
\end{tabular}




\section{Fast Acting Plug Valve: Initial Computations}

- Designed by T. Jones circa early 1990s

- Allows fast turn around between experiments

- $\quad$ Sliding gate valve acts as a safety valve, allowing work on the experimental model while the facility is filled.

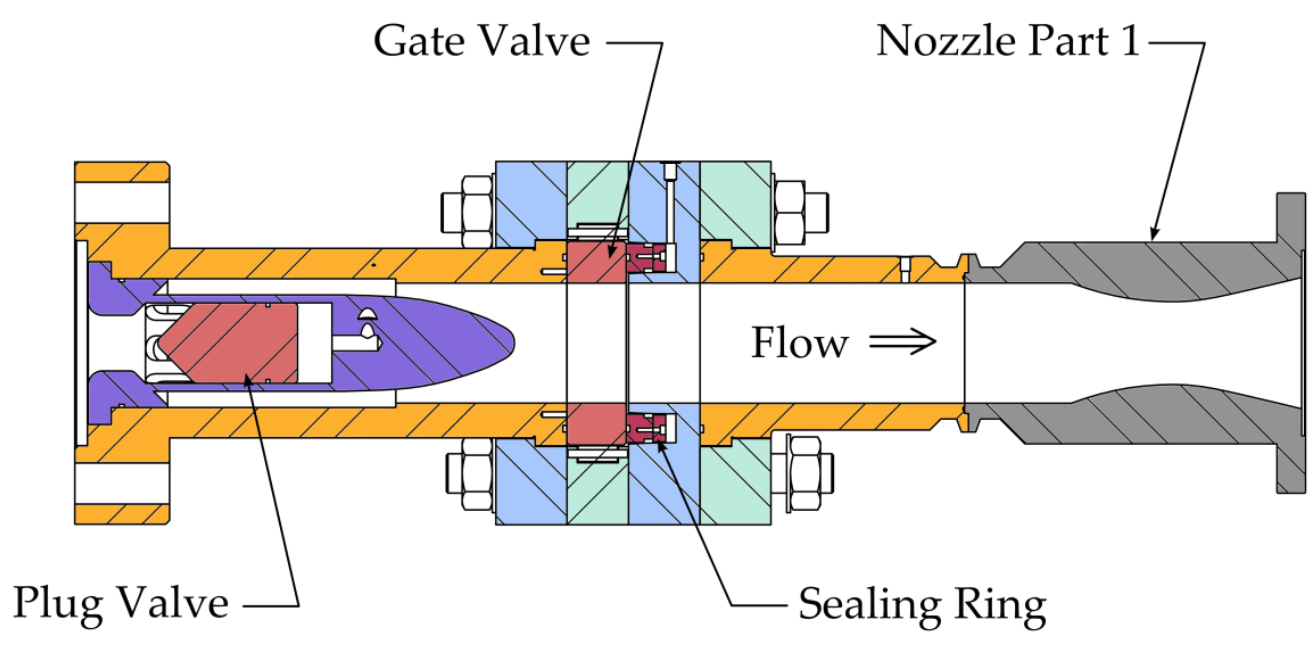

- Simulations completed in CFX

- Spalart-Allmaras turbulence model.

- Simulated a 120deg sector, 11.76 million cells

- Inlet condition: 95 bar, 400K (Mach 6)

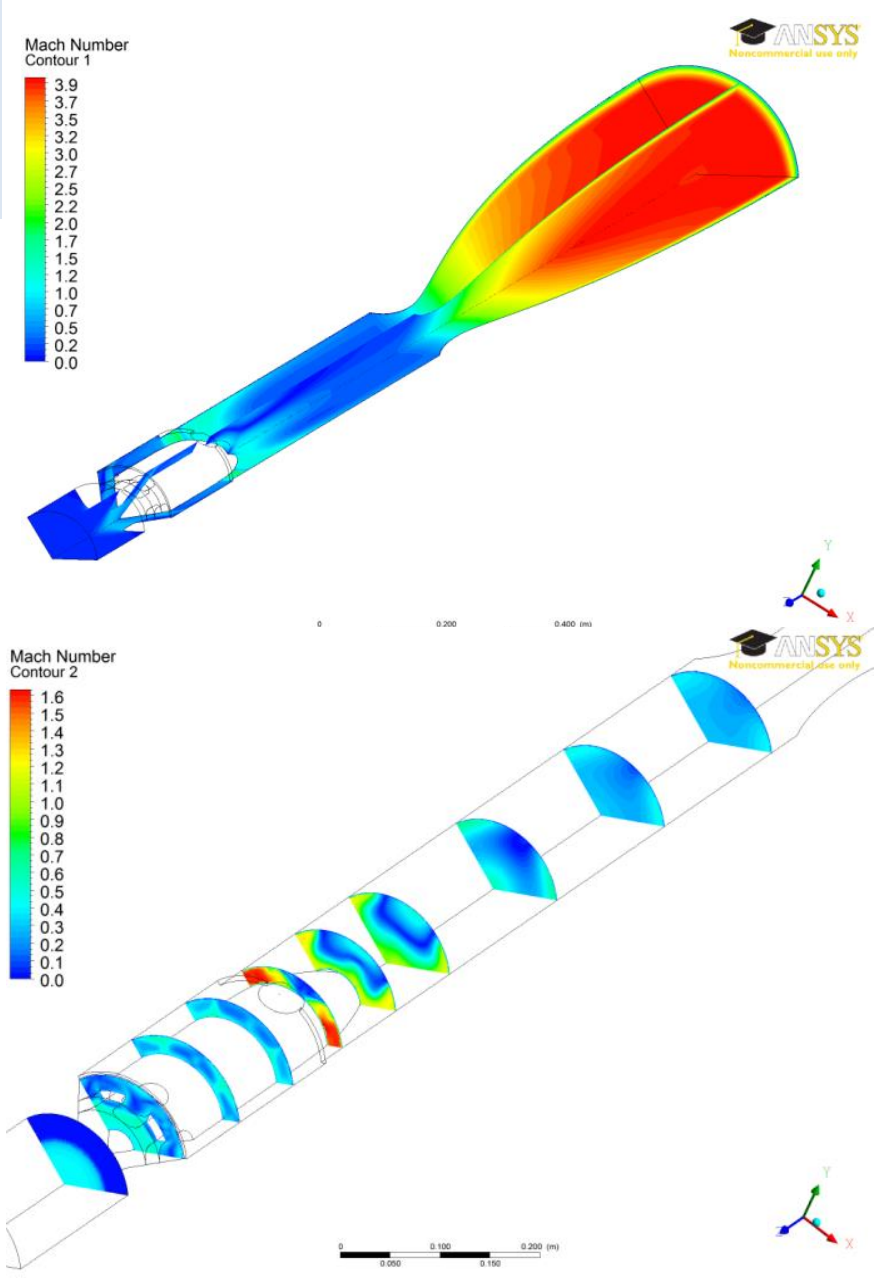


NWTF Fast Acting Plug Valve: Initial Computations

Radial Profiles at the Facility Nozzle Exit (Mach 6)
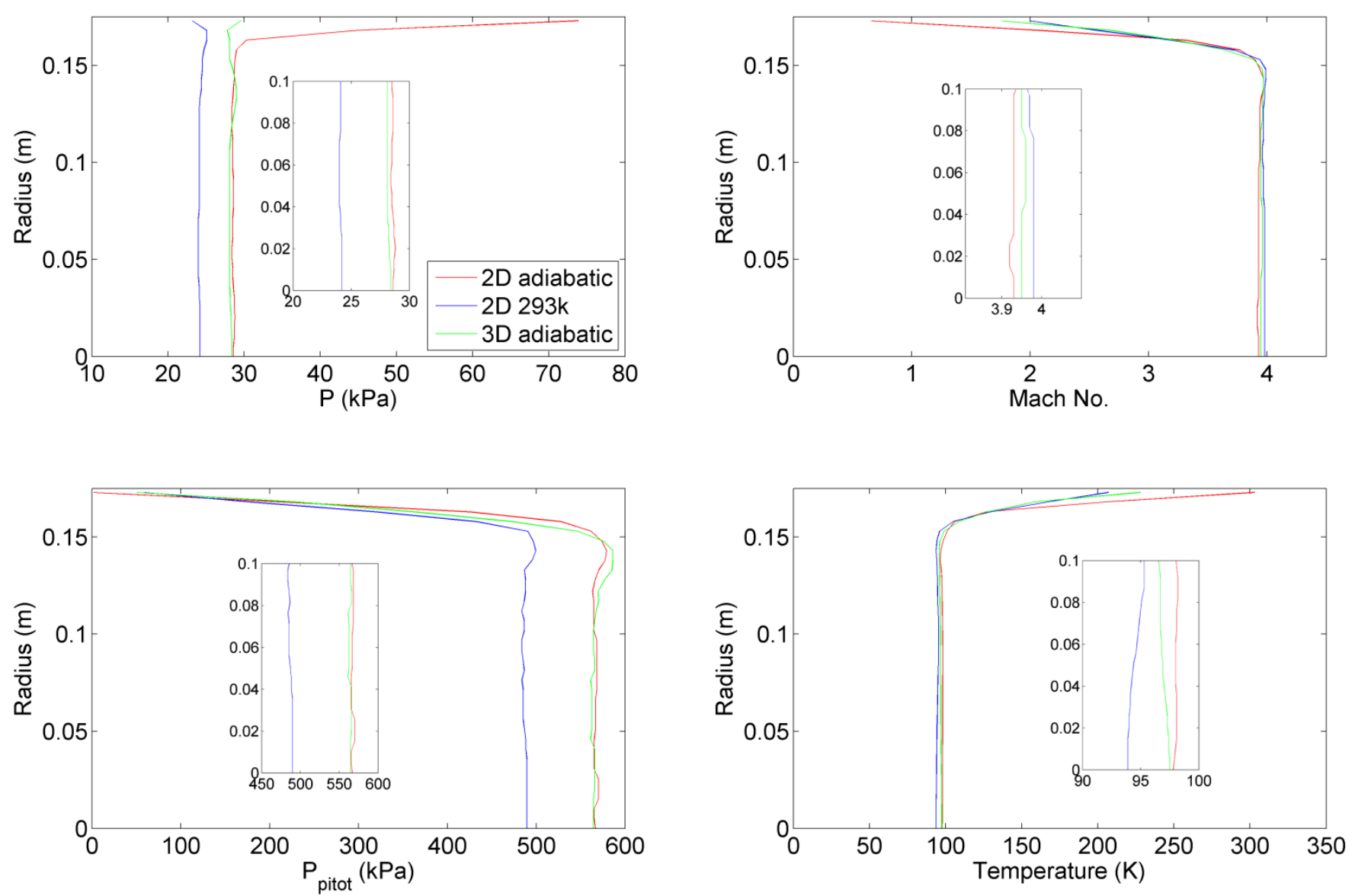


\section{NWTF Available Model Instrumentation/Equipment}

\section{Shared between the T6 Stalker Tunnel \& High Density Tunnel}

Data Acquisition

- Separate NI PXI chassis, 64 channels @ $2 \mathrm{MHz}$ each +128 channels @ $2 \mathrm{MHz}$ aggregate

- LeCoy 4 channel, $5 \mathrm{Ghz}$ oscilliscope

- In-house free flight data acquisition for 6 channels up to $20 \mathrm{kHz}$

Probe measurements

- $16 \times$ PCB-134 pressure transducer (up to 1 $\mathrm{MHz})$

- 24 x Kulite XTL-140M (up to $250 \mathrm{kHz}$ )

- 48 channels of thin film signal conditioning up to $1 \mathrm{MHz}$

- DANTEC 3 hot wire annemometer u to $400 \mathrm{kHz}$

- Advanced thermochromic liquid crystal

Actuated traverse systems by Quadratec Ltd - +/- 20 deg AoA. +/- 10 deg AoY
Optical equipment

- $\quad$ Specialised Imaging Kirana camera (up to 5 $\mathrm{MHz}$ )

- Photron Mini UX-100 camera (up to $1 \mathrm{MHz}$ )

- $\quad$ LED light source up to $1 \mathrm{MHz}$

- Schlieren optics up to $300 \mathrm{~mm}$

Laser Equipment

- Laser Quantum 671 nm DPSS laser (LIGTS)

- Oxiuum low noise $532 \mathrm{~nm}$ DPSS laser (FLDI)

- Continuum Powerlite 8000 Nd:Yag laser (PLIF)
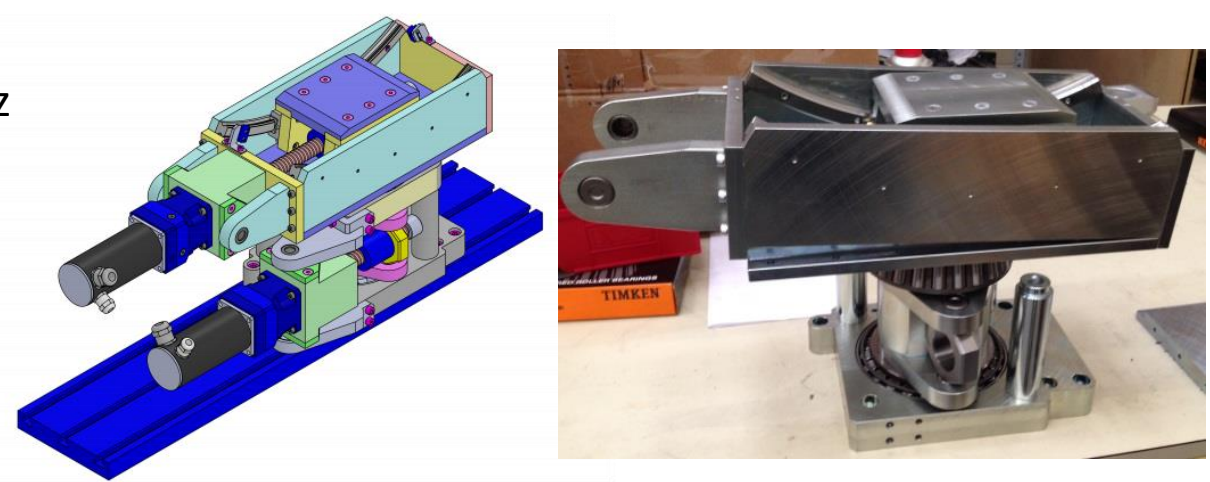
- HDT is a (relatively) long duration, cold hypersonic flow facility

- Installation is actively underway; initial operation expected to begin in the second half of this year.

- The facility will extend the hypersonic testing capabilities of The University of Oxford and complement the high enthalpy T6 Stalker Tunnel (also under development).

- Fast acting plug valve and model re-orientation mechanism allows rapid turn around between experiments

- Preliminary numerical simulations show a large wake flow forms behind the plug valve body but that these damp out by the nozzle exit.

[1] T. V. Jones, P. Street, and M.Westby. Recent enhancement to the DRA shock tunnel. In The European Forum on Wind Tunnels, Southampton, 14 - 17 September 1992.

[2] T. Cain, R. Owen, and C. Walton. Hyshot 2 aerodynamics. In Proceedings of the Fifth European Symposium on Aerothermodynamics for Space Vehicles, number EAS SP-563-229C, Cologne, 8 - 11 November 2005. 